\title{
Emperical Analysis of Productivity of Nigerian Power Sector
}

\author{
${ }^{1}$ Iwuamadi Obioma C., ${ }^{2}$ Dike Damian Obioma \\ ${ }^{1}$ (B. Eng, GMNSE, MIEEE), Department of Electrical and Electronic Engineering, Federal Polytechnic Nekede \\ Owerri. \\ ${ }^{2}$ Electrical and Electronic Engineering Departments, Federal University of Technology, Owerri Imo State.
}

\begin{abstract}
Admittedly, the shocks from the Nigerian electricity crisis despite several palliative measures by the government have created some wedges in the national socio-economic wheel of development. Unfortunately one major method by the government to beef up productivity is by commissioning new power stations which merely solve the problem in the short run. The technical issues that put out the older plants will no sooner than latter affect the new ones and they also go down. This research analyzes the productivity change in Nigeria's power sector from 1970 - 2010. The Malmquist index with Cobb-Douglas Stochastic Production Frontier function was applied to analyze Nigeria's power generation data within the period in focus. Results obtained showed that the 2005 national electric power reform act produced slight technical improvement. It is expected that this work may assist the power policy makers and regulators to come up with better framework for the full realization of the noble goals envisaged in this act.
\end{abstract}

\section{Introduction}

The contribution of energy infrastructure to economic development in general and to industrialization in particular is enormous. It provides the conducive environment for productive activities to take place, allows wider movement of goods and people encourages investment, facilitates information flow and helps diversify the economy. But the deplorable state of most energy infrastructural facilities and the state of disrepair and lack of maintenance especially in electricity, roads, railways and water facilities experienced in Nigeria seems to negate the importance of energy infrastructure. This has resulted in very poor performance in energy infrastructure services.

Energy poverty is the lack of or limited access to energy resources like electricity, gas, fuel, kerosene and diesel. Put differently, it occurs when supply of energy services and goods fall below demand or expectations. Energy poverty is a perennial social problem affecting most developing countries not just Nigeria alone. Statistics shows that 1.6 billion people (one quarter of the world population) have no access to electricity, $80 \%$ of them in South Asia and Sub-Saharan Africa (IEA, 2002). Four out of five people without electricity live in rural areas of the developing countries. About 2.4 billion people in the world lack modern fuels or rely on traditional bio-mass wood, agricultural residues and dung for cooking and heating (Club De Madrid, 2007). Energy poverty or crisis is a major barrier to growth and development in vast areas of the world. This means that many countries wishing to develop and become industrialized, must address their energy challenges and ensure that adequate energy goods and services are provided at affordable cost.

Electricity plays a very important role in the socio-economic and technological development of every nation. The electricity demand in Nigeria far outstrips the supply and the supply is epileptic in nature. The country is faced with acute electricity problems, which is hindering its development notwithstanding the availability of vast natural resources in the country. It is widely accepted that there is a strong correlation between socio-economic development and the availability of electricity. No doubt the epileptic performance of the energy sector, in terms of matching supply with demand expectations, has led to a decline in the living standard of the population and hampered sustainable development in the country. Given the low levels of electricity generation and access in Sub-Saharan Africa, it is not surprising that per capita consumption of electricity averages just $457 \mathrm{KWh}$ annually, with the average falling to $124 \mathrm{KWh}$ if South Africa is excluded (World Bank, 2005). The wide electric energy gap and poverty in comparative regional terms is apparent in per capita electricity consumption in Nigeria being $140 \mathrm{KwH}$ in 2004 compared to $1337 \mathrm{KwH}$ in Egypt and 4560 $\mathrm{KwH}$ in South Africa as at 2003 (Iwayemi .A, 2008). Nigeria's projected per capita consumption of 5000Kwh in 2030 will be about 20\% above the level that obtained in South Africa in 2003.

In spite of Nigeria's huge endowment in energy and the enormous investment in the provision of energy infrastructure, the performance of the power sector remained poor, in comparison with other developing economies. For the past three decades, inadequate quantity, quality and access to electricity services have been a routine feature in Nigeria. An assertion confirmed by a World Bank assessment study conducted on energy development in Nigeria which compared the country's performance in the power sector with those of 20 other developing countries revealed that the sector had the highest percentage of system losses at 33-41\%; the lowest generating capacity factor at $20 \%$; the lowest average revenue at US $\$ 1.56 \mathrm{kWh}$; the lowest rate of return at $8 \%$ 
and the lowest average accounts receivable period of 15 months (World Bank, 1993). Although Nigeria is blessed with large amount of renewable energy resources like hydropower, solar, wind and biomass extensive substitution of poor public electricity supply with highly polluting self-generated power prevail. In fact, Nigeria's economy has been described as a "fuel generator economy" where businesses incur extremely high overhead cost in maintaining their power generators and ensure unsafe health environment by their carbon footprints. Conceptually, the power reforms are aimed at solving a myriad of problems, including limited access to infrastructure, low connection rates, inadequate power generation capacity, poor utilization capacity, and lack of capital for investment, ineffective regulation, high technical losses and vandalism as well as insufficient transmission and distribution facilities (Adenikinju, 1998).

\section{Nigerian Power Sector: Past And Present}

To discuss the power sector in Nigeria in a realistic and practical context, some brief review is necessary to give an insight into the sector since independence.

Nigeria is located on the west coast of Africa. It is the continent's most populated country in Africa, with over 150 million people. The history of electricity in Nigeria dates back to 1896 when electricity was first produced in Lagos, fifteen years after its introduction in Britain from which Nigeria obtained independence in 1960. The total capacity of generators used then was 60KW (Makoju J.O, 2007). In 1929 the Nigerian Electricity Supply Company (NESCO) began operations as an electric utility company in Nigeria with the construction of a hydroelectric power station at Kurra near Jos. The government electricity undertaking was established in 1946, under the jurisdiction of the Public Works Department (PWD) to take over the responsibility of electricity supply in Lagos State (Okoye J.K, 2007).

The first attempt to nationally coordinate the supply and development of electricity occurred in 1950 with the establishment of a central body known as Electricity Corporation of Nigeria, ECN. With the establishment of another body known as Niger Dams Authority (NDA) by an act of the parliament in 1962, the first $132 \mathrm{kV}$ line was constructed, connecting Ijora Power Station to Ibadan Power Station. NDA was responsible for the construction and maintenance of hydro dams and other works on the River Niger and elsewhere generating electricity by means of water power, improving navigation and promoting fish brines and irrigation (Makoju J.O, 2007). It sold electricity to ECN.

In $1^{\text {st }}$ April 1972, the operation of ECN and NDA were merged to form National Electric Power Authority (NEPA) a company with exclusive monopoly over electricity generation, transmission, distribution and sales throughout the country. Since inception of NEPA, the authority expands annually in order to meet the ever-increasing demand. Unfortunately, majority of Nigerians still have no access to electricity and supply to those connected is not regular. Nigeria also joined the trend, having deregulated its electricity industry through the enactment of the Electric Power Reform Act of 2005 (Isola .W.A, 2011). Consequently, Nigeria's defunct National Electric Power Authority (NEPA) is now known as the Power Holding Company of Nigeria (PHCN). The law paved the way for restructuring the power sector by the unbundling of PHCN into 18 companies: six generating companies, one transmission company, and 11 distribution companies and Independent Power Producers (IPP's). The incorporation of these enterprises under the National Integrated Power Project (NIPP) has been concluded. Ironically, though, the electricity crisis has deepened. The present government of Goodluck Jonathan has suspended the NIPP citing constitutional reasons associated with its financing from excess crude funds (Iwayemi A., 2008a).

Despite its long history, PHCN's development has been very slow and electricity generation in Nigeria had deteriorated over the years. This is rarely expected given the country's enormous endowment in natural resources that facilitate and enhance electricity production. While the generation, transmission and distribution (GTD) deteriorated, the demand for electricity exponentially increases continuously. PHCN has been incapable of providing minimum acceptable international standards of electricity service reliability, accessibility and availability for the past three decades (Iwayemi A., 2008[b]).

The typical Nigerian firm experiences power failure or voltage fluctuations about seven times per week, each lasting for about two hours, without the benefit of prior warning (Adeola, A., 2005). This imposes a huge cost on the firm arising from idle workers, destroyed materials, lost output, damaged equipment and restart costs. It is impossible to determine exactly how much of this inefficiency is due to illegal users' tapping the lines, but it seems likely that underinvestment in technology is the greater problem. Nigeria's economy is characterized by a large informal sector many of whom depend on electricity for daily production and livelihood. As PHCN is almost never available many of them have been forced to buy generators to continue production. This immediately has the effect of increasing their cost of production. Those who cannot afford the luxury are forced to abandon the trade often for no visible alternative. The result is that the rate of unemployment continues to rise and rise. The experience in the formal sector is not much different, as corporate bodies have had to self-generate electricity in order to maintain production. 
One method PHCN has used to beef up its actual power output from time to time has been the commissioning of new stations. Experience has shown that new power plants merely solve the problem in the short run. The technical problems that put out the older units no sooner than latter affect the new ones and they also go down (Adeola A., 2008). It would be necessary to find out why the plants perform below expectation. One of the objectives of this study is to evaluate the performance of the country's power generation stations over a period of some time and make recommendations on how to improve its performance.

\section{Literature Survey}

The analysis of a network utility, such as an electricity industry, requires a fundamental rethinking on the way in which the sector is operated and regulated. The basic idea is to analyze and investigate the productivity of Nigeria's power plants and to evaluate the impact of reform on Nigeria's power sector. Studies regarding African Energy companies are a relatively under-researched topic (Estache .A et al, 2008).

Efficiency analysis in relation to electricity has been concentrated on distribution networks. Jamasb and Pollitt reviewed the frequency with which different input and output variables are used to model electricity distribution (2001). The policy implications of surveyed papers focus on the differences in efficiency and drivers of efficiency, the role of alternative regulatory frameworks in efficiency, and the comparative analysis of public and private companies. Kleit and Terrell observed that deregulating electricity generation increases efficiency while Barros and Peypoch states that regulation without competition decreases efficiency (Barros and Peypoch, 2008; Kleit and Terrell, 2000). For competition to work, regulators must coordinate their policy throughout a multi country region, like in South America. A related work by Pollitt observed that privatelyowned plants exhibit higher efficiency than publicly-owned plants (Pollitt, 1996). The most frequently used outputs are units of energy delivered, number of customers and size of the service area. The most widely used inputs are number of employees, transformer capacity and network length.

Research on Nigeria energy includes those on policy and issues, electricity generation, transmission and distribution, cost of infrastructure failure, energy poverty and investments in the power sector (Iwayemi .A, 2008; Garba .B et al, 2009; Adenikinju .A, 2005; Agba .M, 2011). None of these papers analyzed the productivity on Nigerian power plants and evaluated the impact of the reform on the power sector using MATLAB®.

Not restricting the survey to a sample of recent papers on energy production, it is observed that they adopt one of two complementary efficiency methodologies: Data Envelopment Analysis and the Stochastic Frontier Model. It is recognized in literature that both methods give similar ranking and that there is no universally agreed set of input and output variables for modeling of electricity units. This work employed the stochastic frontier model and Malmquist index.

\subsection{MODELS}

The analysis of productivity of a network utility, such as the Nigerian electricity industry requires a fundamental consideration of all factors of electricity production. This research analysis is with keen interest in electricity generation in Nigeria.

\section{TOTAL FACTOR PRODUCTIVITY INDEX}

For a given plant(s), the production characteristics are defined as:

- Load factor: this is ratio of the number of units actually generated in a given period to the number of units which could have been generated with the same maximum demand (operable capacity). It is an indication of the utilization of power plant capacity. A high load factor means that the plant capacity is utilized for most of the time and is desirable from the point of view of reducing cost of generation per unit of energy produced (Ekeh .J, 2001; Kofoworola, 2003). The reduction in cost with good load factor is due to the fact that overall working cost per unit becomes low, a fixed charge having been distributed over more units of energy generated. The load factor international best practice value is $80 \%$ (Akinbulire et al., 2007).

Load factor is given as (Isaac .F .O et al., 2011):

$$
\text { Load Factor, } L_{F}=L_{a v} / L_{o p}
$$

Where:

$L_{a v}=$ average load generated.

$L_{\text {op }}=$ average operational capacity.

- Utilization factor: this reflects how effectively managed the plant(s) are in terms of down time. It measures the use made of the total installed capacity of the plant(s). It is the ratio of maximum load generation in a given period to the plant(s) installed capacity. The international best practice is 95\% (Eheh .J, 2001). 
The utilization factor is given as (Isaac .F .O et al., 2011):

Utilization Factor, $\mu_{f}=L_{m x} / C_{i n}$

Where:

$L_{m x}=$ maximum load generated.

$C_{\text {in }}=$ total installed capacity.

- Capacity factor: this indicates the degree of plant(s) failure. It is the ratio of average energy output of the plant(s) for a given time period to the plant(s) installed capacity. It measures the extent of use of the generating plant(s). A low capacity factor signifies that average energy generation is low and that most of its capacity remains unutilized for most part of the period under consideration, so cost will be high. A high capacity factor is desired for economic operation of plant. The international best practice is $50 \%-80 \%$ (Ekeh .J, 2001; Kofoworola, 2003).

The capacity factor can be obtained with (Isaac .F .O et al., 2011):

Capacity Factor $\alpha_{f}=E_{p} /\left(C_{i n} * T_{h}\right)$

Where:

$C_{\text {in }}=$ total installed capacity.

$E_{p}=$ total electrical energy produced.

$T_{h}=$ total number of operational hours.

Re-arranging equations 3.2 and 3.3 gives

$C_{i n}=L_{m x} / \mu_{f}$

$C_{i n}=E_{p} /\left(\alpha_{f} * T_{h}\right)$

Equating 3.4 and 3.5 gives the total factor productivity index $A_{f}$ as

$A_{f}=\left(\mu_{f} / \alpha_{f}\right)=\left[\left(L_{m x} * T_{h}\right) / E_{p}\right]$

Equation 3.6 can be written as

$\mu_{f}=\alpha_{f}\left[\left(L_{m x} * T_{h}\right) / E_{p}\right]$

The slope of the graph of $\mu_{f}$ against $\alpha_{f}$ is the total factor productivity.

Equation 3.6 can also be re-arranged as:

$P_{l}=\left(\alpha_{f} * L_{m x}\right)=\left[\left(\mu_{f} * E_{p}\right) / T_{h}\right]$

Where $P_{l}$ is the maximum loss power at down time. Equation 3.8 can also be written as:

$\alpha_{f}=1 / L_{m x}\left[\left(\mu_{f} * E_{p}\right) / T_{h}\right]$

The slope of the graph of $\alpha_{f}$ against $1 / L_{m x}$ is $P_{l}$.

\subsection{COBB-DOUGLAS STOCHASTIC PRODUCTION FRONTIER MODEL}

If the production function is denoted by $\mathrm{P}(\mathrm{L}, \mathrm{K})$, then the partial derivative 
$\partial \mathrm{P} / \partial \mathrm{L}$, is the rate at which production changes with respect to the amount of labor. Economists call it the marginal production with respect to labor or the marginal productivity of labor. Likewise, the partial derivative $\partial \mathrm{P} / \partial \mathrm{K}$ is the rate of change of production with respect to capital and is called the marginal productivity of capital (Wikipedia).

In these terms, the assumptions made by Cobb and Douglas can be stated as follows:

1. If either labor or capital vanishes, then so will production.

2. The marginal productivity of labor is proportional to the amount of production per unit of labor.

3. The marginal productivity of capital is proportional to the amount of production per unit of capital.

Because the production per unit of labor is $\mathrm{P} / \mathrm{L}$, assumption 2 says that $\partial \mathrm{P} / \partial \mathrm{L}=\alpha[\mathrm{P} / \mathrm{L}]$, for some constant $\alpha$. If we keep $\mathrm{K}$ constant $\left(\mathrm{K}=\mathrm{K}_{0}\right)$ then this partial differential equation becomes an ordinary differential equation:

$\mathrm{dP} / \mathrm{dL}=\alpha[\mathrm{P} / \mathrm{L}]$

This separable differential equation can be solved by re-arranging the terms and integrating both sides:

$\int 1 / \mathrm{P} d \mathrm{P}=\alpha \int 1 / \mathrm{L} d \mathrm{~L}$

$\ln (\mathrm{P})=\alpha \ln (\mathrm{CL})$

$\ln (\mathrm{P})=\ln (\mathrm{cL})^{\alpha}$

And finally,

$\mathrm{P}\left(\mathrm{L}, \mathrm{K}_{0}\right)=\mathrm{C}_{1}\left(\mathrm{~K}_{0}\right) \mathrm{L}^{\alpha}$

Where $\mathrm{C}_{1}\left(\mathrm{~K}_{0}\right)$ is the constant of integration and we write it as a function of $\mathrm{K}_{0}$ since it could depend on the value of $\mathrm{K}_{0}$.

Similarly, assumption 3 says that

$\partial \mathrm{P} / \partial \mathrm{K}=\beta[\mathrm{P} / \mathrm{K}]$

Keeping $\mathrm{L}$ constant $\left(\mathrm{L}=\mathrm{L}_{0}\right)$, this differential equation can be solved to get:

$\mathrm{P}\left(\mathrm{L}_{0}, \mathrm{~K}\right)=\mathrm{C}_{2}\left(\mathrm{~L}_{0}\right) \mathrm{K}^{\beta}$

Finally combining equations (3.12) and (3.13) gives:

$\mathrm{P}(\mathrm{L}, \mathrm{K})=\mathrm{bL}^{\alpha} \mathrm{K}^{\beta}$

Where $\mathrm{b}$ is a constant that is independent of both $\mathrm{L}$ and $\mathrm{K}$.

Assumption 1 shows that $\alpha>0$ and $\beta>0$.

Notice from equation (3.14) that if labor and capital is both increased by a factor $\mathrm{m}$, then

$\mathrm{P}(\mathrm{mL}, \mathrm{mK})=\mathrm{b}\left(\mathrm{mL}^{\alpha}\right)\left(\mathrm{mK}^{\beta}\right)$

$=\mathrm{m}^{\alpha+\beta} \mathrm{bL}^{\alpha} \mathrm{K}^{\beta}$

$=\mathrm{m}^{\alpha+\beta} \mathrm{P}(\mathrm{L}, \mathrm{K})$

If $\alpha+\beta=1$, then $\mathrm{P}(\mathrm{mL}, \mathrm{mK})=\mathrm{mP}(\mathrm{L}, \mathrm{K})$, which means that production is also increased by a factor of $m[34]$.

Cobb-Douglas stochastic production frontier function is as written in equation (3.14)

$\mathrm{P}(\mathrm{L}, \mathrm{K})=\mathrm{bL}^{\alpha} \mathrm{K}^{\beta}$

Where: 
- $\mathrm{P}=$ total production (the monetary value of all goods produced in a year)

- $\mathrm{L}=$ labor input (the total number of person-hours worked in a year)

- $\mathrm{K}$ = capacity input (the installed capacity of equipments)

$\cdot \mathbf{b}=$ total factor productivity.

- $\alpha$ and $\beta$ are the output elasticity's of labor and capital, respectively. These values are constants determined by available technology in a given period.

Output elasticity measures the responsiveness of output to a change in levels of either labor or capital used in production.

Further, if:

$\alpha+\beta=1$, the production function has constant returns to scale. That is, if $\mathrm{L}$ and $\mathrm{K}$ are each increased by $20 \%$, then P increases by $20 \%$.

Returns to scale refers to a technical property of production that examines changes in output subsequent to a proportional change in all inputs (where all inputs increase by a constant factor). If output increases by that same proportional change then there is constant returns to scale (CRTS), sometimes referred to simply as returns to scale. If output increases by less than that proportional change, there are decreasing returns to scale (DRS). If output increases by more than that proportion, there are increasing returns to scale (IRS) (Bao Hong, Tan, 2008).

However, if $\alpha+\beta<1$, returns to scale are decreasing, and if $\alpha+\beta>1$, returns to scale are increasing. Assuming perfect competition, $\alpha$ and $\beta$ can be shown to be labor and capital's share of output.

\subsection{MALMQUIST INDEX}

This is a bilateral index that enables a productivity comparison between two different entities of similar category. These entities could be economy, firms, processes e.t.c. It is based on the concept of production function - a function of maximum possible production, with respect to a set of inputs pertaining to capital and labor (en.wikipedia.org).

Assume that the aggregate production function for an entity is given as $\mathrm{P}(\mathrm{L}, \mathrm{K})$. Then for entity A, we have the aggregate production function as $\mathrm{P}_{\mathrm{A}}\left(\mathrm{K}_{\mathrm{A}}, \mathrm{L}_{\mathrm{A}}\right)$ and for entity $\mathrm{B}$, we have $\mathrm{P}_{\mathrm{B}}\left(\mathrm{K}_{\mathrm{B}}, \mathrm{L}_{\mathrm{B}}\right)$.

$\mathrm{K}$ and $\mathrm{L}$ describe the capacity and labor inputs respectively.

Substituting the inputs of $\mathrm{B}$ into the production function of A, results to

$P_{A}\left(K_{B}, L_{B}\right)$ and the inputs of $A$ into $B$ to get $P_{B}\left(K_{A}, L_{A}\right)$. The Malmquist index of $A$ with respect to $B$ is the geometric mean of $\mathrm{P}_{A}\left(\mathrm{~K}_{\mathrm{A}}, \mathrm{L}_{\mathrm{A}}\right) / \mathrm{P}_{\mathrm{A}}\left(\mathrm{K}_{\mathrm{B}}, \mathrm{L}_{\mathrm{B}}\right)$ and $\mathrm{P}_{\mathrm{B}}\left(\mathrm{K}_{\mathrm{A}}, \mathrm{L}_{\mathrm{A}}\right) / \mathrm{P}_{\mathrm{B}}\left(\mathrm{K}_{\mathrm{B}}, \mathrm{L}_{\mathrm{B}}\right)$.

Mathematically Malquist Index, MI is stated as:

$M I=\sqrt[2]{\frac{P_{A}\left(K_{A}, L_{A}\right) * P_{B}\left(K_{A}, L_{A}\right)}{P_{A}\left(K_{B}, L_{B}\right) * P_{B}\left(K_{B}, L_{B}\right)}}$

\subsection{DATA SOURCE}

This analysis made use of dataset on all the existing Nigerian electricity plants from 1970 to 2010 from several sources. The sources of the data are the Power Holding Company of Nigeria generation report from 1970 to 2010, National Control Center PHCN Oshogbo, Central Bank of Nigeria Statistical bulletin (2004), publications of Nigerian Ministry of Power and Steel. However data gaps are filled with other sources such as Energy Commission of Nigeria, Energy Information Administration and CIA World Fact Books, National Power Training Institute of Nigeria (NAPTIN). The year 2001 is used as the base year for productivity analysis of the Nigerian Power Sector. The choice of this year is informed by the fact that the National Electric Power Policy (NEPP) was enacted in 2001 and subsequent policies and reforms followed suit in the power sector.

\subsection{SPECIFICATIONS OF PRODUCTION MODEL}

This research made the following assumptions:

(1) Human labor and installed capacity as the input variables in the stochastic frontier.

(2) Total electrical energy produced, average load generated and maximum load generated as output variables in the stochastic frontier model. 
(3) A constant return to scale for the production function.

(4) At least a power plant is operational at every second of the day.

(5)

\subsection{ESTIMATION OF MODELS}

Assuming time period $\mathrm{t}$ from 1970 to 2010 defined with specific intervals as shown in table 1 .

For the years (periods) stated above, $\mathrm{t}=1,2,3,4, \ldots 18$. Hence the factors of production from equations (3.1), (3.2), (3.3) and (3.6) are given as:

Load Factor, $\mathrm{L}_{\mathrm{F}}^{\mathrm{t}}=\mathrm{L}_{\mathrm{av}}^{\mathrm{t}} / \mathrm{L}_{\mathrm{op}}^{\mathrm{t}}$

Utilization Factor,$\mu_{\mathrm{F}}^{\mathrm{t}}=\mathrm{L}_{\mathrm{mx}}^{\mathrm{t}} / \mathrm{C}_{\mathrm{in}}^{\mathrm{t}}$

Capacity Factor,$\alpha_{\mathrm{F}}^{\mathrm{t}}=\mathrm{E}_{\mathrm{p}}^{\mathrm{t}} / \mathrm{C}_{\mathrm{in}}^{\mathrm{t}} * \mathrm{~T}_{\mathrm{h}}^{\mathrm{t}}$

Total factor productivity,$A_{f}^{\mathrm{t}}=\mu_{\mathrm{F}}^{\mathrm{t}} / \alpha_{\mathrm{F}}^{\mathrm{t}}$

Where,

$\mathrm{T}_{\mathrm{h}}^{\mathrm{t}}=24 \mathrm{hrs} * 365$ days $($ annual analysis) $=8760 \mathrm{hrs}$

Let the production technology of Nigerian power stations in time $t$, be denoted as $\rho_{t}$ which represents the transformation inputs $\left(X^{t} \in R^{m}\right)$ into the outputs $\left(Y^{t} \in R^{k}\right)$. $\rho_{t}=\left\{\left(X^{t}, Y^{t}\right): X^{t}\right.$ can produce $\left.Y^{t}\right\}$.

$\left\{\left(K_{t}, H_{t}\right) \in X^{t}\right\}$ where $\mathrm{K}$ and $\mathrm{H}$ are installed capacity and human labor respectively.

$\left\{\left(E_{p}, L_{a v}, L_{m x}\right) \in Y^{t}\right\}$

$R^{m}$ and $R^{k}$ are all the inputs and outputs respectively.

Assuming constant return to scale of the input variables in consideration, an algorithm for human labor is given as:

$H_{j}=\left|\left(\frac{K_{j}-K_{j-1}}{K_{j-1}}\right) H_{j-1}+H_{j-1}\right|_{j=2,3,4,5, \ldots \ldots, 18}$

The output Cobb-Douglas stochastic production frontier function at time period $t$ is defined as:

$F_{t}\left(K_{t}, H_{t}\right)=A_{t} * K_{t}^{\alpha_{t}} * H_{t}^{\left(1-\alpha_{t}\right)}$
$\left\{\left(K_{t}, H_{t_{s}}\right): K_{t} \geq 0, H_{t} \geq 0\right\}$

The output Cobb-Douglas stochastic production frontier function at time period $t+1$ is defined as:

$F_{t+1}\left(K_{t+1}, H_{t+1}\right)=A_{t+1} * K_{t+1}^{\alpha_{t+1}} * H_{t+1}^{\left(1-\alpha_{t+1}\right)}$

(3.20a)

$\left\{\left(K_{t+1}, H_{t+1}\right): K_{t+1} \geq 0, H_{t+1} \geq 0\right\}$

The period $t+1$ can be any other time period under consideration not necessarily immediately after $t$. To access changes in productivity over time, mixed period Cobb-Douglas stochastic production frontier functions is defined as:

$$
\begin{aligned}
& F_{t}\left(K_{t+1}, H_{t+1}\right)=A_{t+1} * K_{t+1}^{\alpha_{t}} * H_{t+1}^{\left(1-\alpha_{t}\right)} \\
& F_{t+1}\left(K_{t}, H_{t}\right)=A_{t} * K_{t}^{\alpha_{t+1}} * H_{t}^{\left(1-\alpha_{t+1}\right)}
\end{aligned}
$$


Productivity change between periods $t$ and $t+l$ can be measured relative to time period $t$ as $M_{t}$ or relative to time period $t+1$ as $M_{t+1}$, where

$$
\begin{aligned}
& M_{t}=\left[\frac{F_{t}\left(K_{t+1}, H_{t+1}\right)}{F_{t}\left(K_{t}, H_{t}\right)}\right] \\
& M_{t+1}=\left[\frac{F_{t+1}\left(K_{t+1}, H_{t+1}\right)}{F_{t+1}\left(K_{t}, H_{t}\right)}\right]
\end{aligned}
$$

The Malmquist productivity change index between $t$ and $t+1$ is defined as the geometric mean of $M_{t}$ and $M_{t+1}$. This is given as:

$$
M A L M=\sqrt[2]{M_{t} * M_{t+1}}=\sqrt[2]{\left[\frac{F_{t}\left(K_{t+1}, H_{t+1}\right)}{F_{t}\left(k_{t}, H_{t}\right)}\right] *\left[\frac{F_{t+1}\left(K_{t+1}, H_{t+1}\right)}{F_{t+1}\left(K_{t}, H_{t}\right)}\right]}
$$

If this index exceeds unity, it indicates that there has been improvement in productivity between period $t$ and $t+1$. Values less than unity suggest regression.

Equation (3.23a) can be simplified further as:

$$
M A L M=\left[\frac{F_{t+1}\left(K_{t+1}, H_{t+1}\right)}{F_{t}\left(K_{t}, H_{t}\right)}\right]\left[\sqrt[2]{\left[\frac{F_{t}\left(K_{t+1}, H_{t+1}\right)}{F_{t+1}\left(K_{t+1}, H_{t+1}\right)}\right] *\left[\frac{F_{t}\left(K_{t}, H_{t}\right)}{F_{t+1}\left(K_{t}, H_{t}\right)}\right]}\right]
$$

Where,

Technical efficiency, TEFFC $=\left[\frac{F_{t+1}\left(K_{t+1}, H_{t+1}\right)}{F_{t}\left(K_{t}, H_{t}\right)}\right]$

Technological progress, $T E C H C=\left[\sqrt[2]{\left[\frac{F_{t}\left(K_{t+1}, H_{t+1}\right)}{F_{t+1}\left(K_{t+1}, H_{t+1}\right)}\right] *\left[\frac{F_{t}\left(K_{t}, H_{t}\right)}{F_{t+1}\left(K_{t}, H_{t}\right)}\right]}\right]$

Equation (3.24) can be summarized as:

\section{$M A L M=T E F F C * T E C H C$}

TEFFC measures the "catching up" to the frontier isoquant i.e change in technical efficiency over the two periods. TEFFC is defined as the diffusion of best-practice technology in the management of activity (Ade .I et al., 2011). This is attributed to investment planning, technical experience and management and organization in power stations.

TECHC measures the shift in the frontier isoquant from one period to another i.e. change in technology over the two periods. As a consequence of innovation, technological change occurs, that is adoption of new technologies by best-practice power plant (Ade .I et al., 2011). This also reveals the effect of routine maintenance on the plants. If the values of either of these components is greater than unity (>1) suggests improvement but if otherwise suggests the opposite (Ade .I et al., 2011; Färe, R et al., 1998).

Using year $2001(t=12)$ as a benchmark year to compare productivity change before and after the Nigerian power sector reforms, equations (3.24a) and (3.24b) becomes:

$$
\begin{aligned}
& T E F F C_{(t, 12)}=\left[\frac{F_{t}\left(K_{t}, H_{t}\right)}{F_{12}\left(K_{12}, H_{12}\right)}\right]_{\mathrm{t}=1,2,3, \ldots+18} \\
& \operatorname{TECHC}_{(t, 12)}=\left[\sqrt[2]{\left[\frac{F_{12}\left(K_{t}, H_{t}\right)}{F_{t}\left(K_{t}, H_{t}\right)}\right] *\left[\frac{F_{12}\left(K_{12}, H_{12}\right)}{F_{t}\left(K_{12}, H_{12}\right)}\right]}\right]_{t=1,2,3, \ldots+18} \\
& \operatorname{MALM}_{(t, 12)}=\operatorname{TEFFC}_{(t, 12)} * T E C H C_{(t, 12)}
\end{aligned}
$$

To investigate periodic rate of productivity change of the Nigerian power sector during the post-reform era, equations (3.24a) and (3.24b) becomes:

$\operatorname{TEFFC}_{(i, i+1)}=\left[\frac{F_{i+1}\left(K_{i+1}, H_{i+1}\right)}{F_{i}\left(K_{i}, H_{i}\right)}\right]_{i=12,13,14, \ldots .17}$ 
$\operatorname{TECHC}_{(i, i+1)}=\left[\sqrt[2]{\left[\frac{F_{i}\left(K_{i+1}, H_{i+1}\right)}{F_{i+1}\left(K_{i+1}, H_{i+1}\right)}\right] *\left[\frac{F_{i}\left(K_{i}, H_{i}\right)}{F_{i+1}\left(K_{i}, H_{i}\right)}\right]}\right]_{i=12,13,14, \text {, } 17}$

$\operatorname{MALM}_{(i, i+1)}=\operatorname{TEFFC}_{(i, i+1)} * \operatorname{TECHC}_{(i, i+1)}$

MATLAB program used to model these analyses is shown in appendix

\section{Emperical Results}

This section presents the empirical results from the analytical models. Productivity change indexes were conducted with the models using year 2001 as the benchmark year. These results are presented and analyzed in four separate sections.

\subsection{PRODUCTIVITY FACTOR RESULTS}

Table 1 presents results for annual average factors of production evidenced in Nigeria's Power Sector as considered in the research. The table shows that the plants' load factor attained $80 \%$ (best practice value) only in 2004 and 2010 while the utilization factor and capacity factor is abysmally low compared with the international best practice value of $95 \%$ and $50 \%$ to $80 \%$ respectively. The available generated energy for the periods under review is a far cry from the installed capacity. Before the Power Sector Reform in 2001, the peak

\begin{tabular}{|l|l|l|l|l|l|l|}
\hline YEAR & $\mathbf{L}_{\mathbf{F}}$ & $\boldsymbol{\mu}_{\mathbf{F}}$ & $\boldsymbol{\alpha}_{\mathbf{F}}$ & $\mathbf{A}_{\mathbf{F}}$ & $\mathbf{P}_{\mathbf{L}}(\mathbf{M W})$ & $\mathbf{R}_{\mathbf{a}}(\boldsymbol{\%})$ \\
\hline 1970 & 0.58380 & 0.21946 & 0.21946 & 1.0000 & 38.756 & 4.82 \\
\hline 1973 & 0.73566 & 0.34425 & 0.32689 & 1.0531 & 97.908 & 11.25 \\
\hline 1976 & 0.60487 & 0.41655 & 0.38045 & 1.0949 & 178.32 & 15.85 \\
\hline 1980 & 0.55350 & 0.36543 & 0.29295 & 1.2474 & 238.78 & 10.71 \\
\hline 1983 & 0.67342 & 0.33638 & 0.32647 & 1.0304 & 324.70 & 10.98 \\
\hline 1986 & 0.70401 & 0.30600 & 0.30315 & 1.0094 & 372.55 & 9.28 \\
\hline 1990 & 0.68777 & 0.33793 & 0.33544 & 1.0094 & 515.53 & 11.34 \\
\hline 1993 & 0.71642 & 0.36403 & 0.36689 & 0.9922 & 607.42 & 13.36 \\
\hline 1996 & 0.73840 & 0.40770 & 0.40087 & 1.0170 & 743.30 & 16.34 \\
\hline 1999 & 0.75689 & 0.33330 & 0.33328 & 1.0001 & 619.83 & 11.12 \\
\hline 2000 & 0.69505 & 0.31152 & 0.31151 & 1.0000 & 541.50 & 9.70 \\
\hline 2001 & 0.68649 & 0.36240 & 0.36082 & 1.0044 & 729.64 & 13.08 \\
\hline 2003 & 0.74225 & 0.41926 & 0.41768 & 1.0038 & 1082.2 & 17.51 \\
\hline 2004 & 0.80393 & 0.44718 & 0.44576 & 1.0032 & 1231.9 & 19.93 \\
\hline 2005 & 0.72856 & 0.42291 & 0.42291 & 1.0001 & 1167.4 & 17.88 \\
\hline 2006 & 0.72267 & 0.39260 & 0.39109 & 1.0039 & 1044.3 & 15.35 \\
\hline 2007 & 0.70592 & 0.32528 & 0.33790 & 0.9626 & 869.90 & 10.99 \\
\hline 2010 & 0.91424 & 0.45806 & 0.45180 & 1.0139 & 1678.9 & 20.70 \\
\hline
\end{tabular}

ratio of available energy was just $40.7 \%$ to total installed capacity in 1996.

The ratio fell to $36.2 \%$ in 2001 with a non appreciable increase to $45.8 \%$ in 2010 . This shows an average annual load factor growth rate ratio of $1.06 \%$ for nine years. The implication is that there is a large gap between installed and actual operational capacity of the power stations which may be due to aging generating facilities that are poorly maintained.

The load factor indicates the utilization of the power plant's capacity. A high load factor means that the total plant operable capacity is utilized most of the time and is desirable from the point of view of reducing cost of generation per unit of energy produced (Ekeh .J, 2001; Kofoworola , 2003). The reduction in cost with good load factor is due to the fact that overall working cost per unit becomes low, the fixed charges having been distribution over more units of energy generated. The low load factor shows poor turn around maintenance on power plants as and when due.

The variation in utilization factor in the periods under review is shown in Figure 2. The utilization factor had been on fluctuating increase ranging from 0.21946 in 1970 to 0.36240 in 2001 and to 0.44718 in 2004. This trend of utilization factor reflects how effectively managed the power stations are in terms of downtime. It was observed that some plants were under utilized for their normal hours of utilization all year round. At different times some of the plants were inevitably idle for such reasons as undergoing routine maintenance/inspection and fault development. 


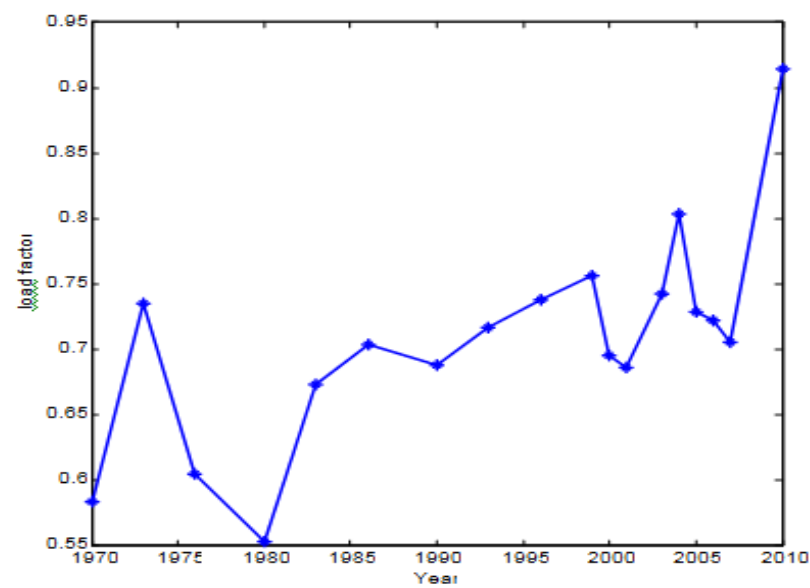

However, the network is likely to have more downtime than the plants and is likely to be called upon to generate for less time than it is available.

The sector witnessed a peak utilization factor of 0.45168 in 2010 as against international best practice value of 0.95 (95\%). This slight improvement is attributed to the rehabilitation of existing generating units, installation of new generating plants and the procurement of power from independent operators (Makoju, 2002; Agbo, 2007). Planned and routine maintenance should be carried out to reduce incidence of downtime.

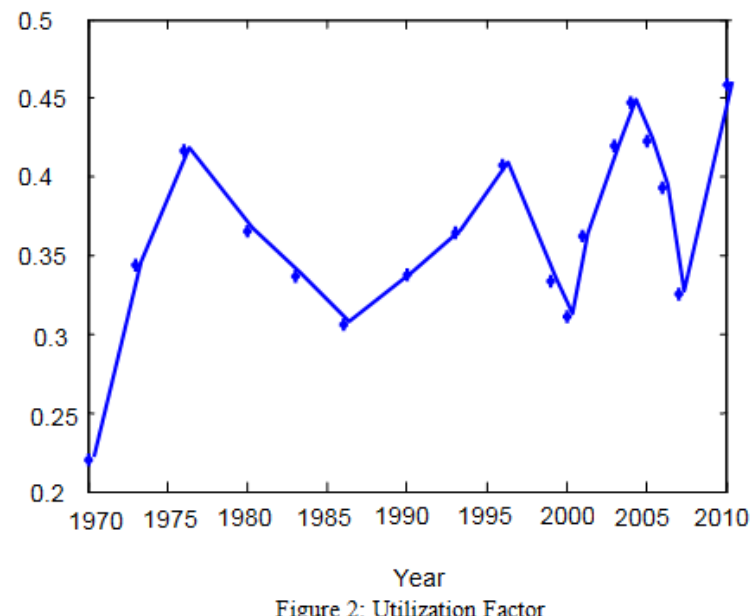

The annual variation of capacity factor of the power stations is as presented in Figure 3. The capacity has been abysmally low in the periods under review with a minimum of 0.21946 in 1970 and a maximum of 0.44576 in 2004 as against the international best practice value of 0.5 to 0.80 . It should be noted that a low capacity factor signifies that the average energy generation is low (Ekeh .J, 2001; Kofoworola, 2003). This could indicate excessive plant failure. This means that most of the power stations' capacity remains unutilized for major part of the years under review, so the cost will be high. This evidenced by the regular and prolonged power outages in the power sector. High value of capacity factor is desired for economic operation of the power stations (Akinbulire et al., 2007). However, the actual power available at any given time under the reviewed period was less than $46 \%$ of the total installed capacity due to poor maintenance and out of date technology. Poor maintenance culture, even if it does not lead to frequent failure can at least increase the overall operating cost. If scheduled maintenance of the plants is significantly improved, high capacity factor will appear attainable given the exogenous sourcing of the needed spare parts. The characteristic behavior of the power stations depends substantially on the capacity factor and utilization factor of the plants in it.

The total factor productivity index shows the effect of plant downtime on its output with respect to its operable state. The value has no implication on plant performance. The variation of total factor productivity is as presented in Figure 4. 


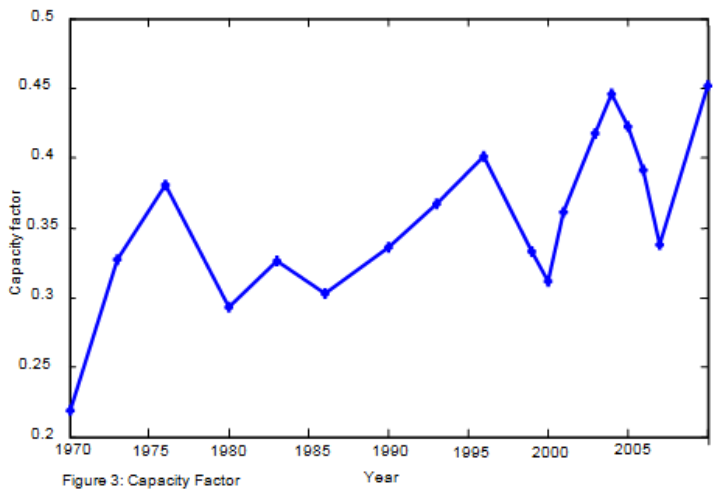

Variation of annual maximum loss power at downtime is as shown in Figure 5. The annual maximum loss power has been on the increase ranging from 38.756MW in 1970 to $729.64 \mathrm{MW}$ in 2001 . This reflects the maximum power that can be lost at downtime. There is gradual increase trend to $1655.5 \mathrm{MW}$ in 2010 . The power plant downtime has been on constant deteriorating mode either as a result of insufficient routine maintenance/inspection and fault development or network failure or theft. In 2009, the power sector lost 450MW due to vandalisation of Okoloma gas station which supplies gas to Afam power station (Omachonu J. and Chiejine A., 2009).

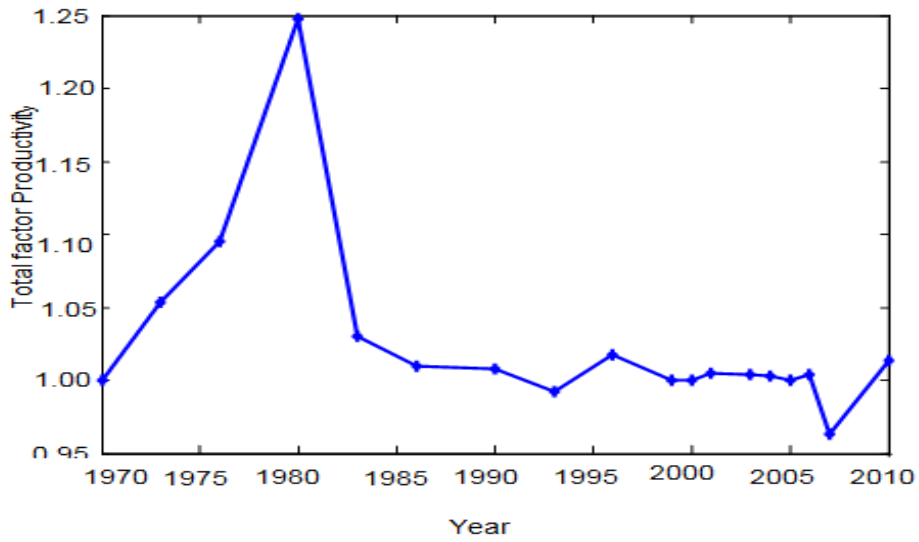

Figure 6 shows the variation in maximum unavailability ratio index. This index is the ratio of maximum power loss with installed capacity. This indicates that at maximum about $4.82 \%$ of installed capacity was unavailable at each downtime in 1970. The trend in increase shows that little or nothing has been done to ensure the power plants optimum availability from $4.82 \%$ in 1970 to $13.07 \% 0102001$ and to a weeping state of $20.70 \%$ in 2010 . Unavailability of power plants due to insufficient gas supply in 2009 cost the power sector about 2000MW (Omachonu J. and Chiejine A., 2009).

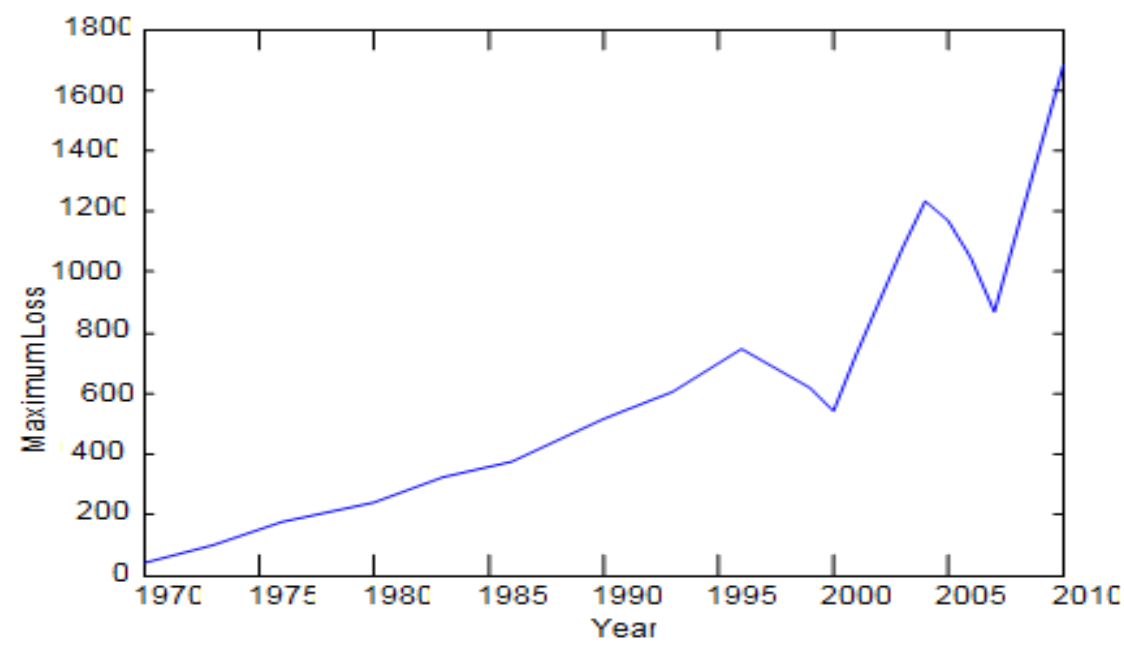




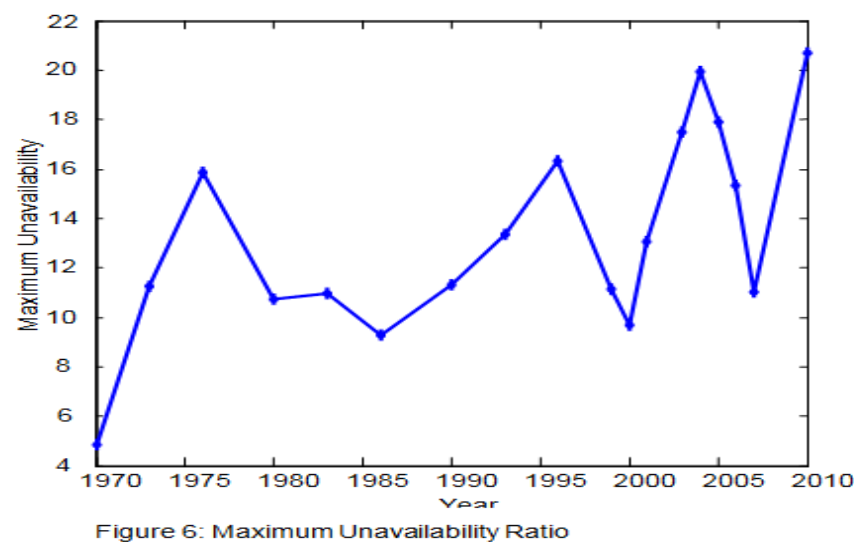

\subsection{EFFICIENCY RESULTS}

The results of the productivity change index are presented in Table 2. This shows the annual productivity change over the period under review using year 2001 as the base year. The productivity change index also referred to as Malmquist index is decomposed into two separate indexes measuring technical efficiency change and technological change. The result shows that TECHC and TEFFC for the year 2001 is unity, this proves it as the base year for comparison. The MALM shown in Figure 9 has been on the increase ranging from 0.14360 in 1970 to 1.4793 in 2010. The sector experienced an average index increase in productivity of 0.8564 from 1970 to 2001 and 0.4793 from 2001 to 2010 . The annual average increase rate is $2.7 \%$ and $5.3 \%$ before and after the reform respectively. This rate of increase is relatively poor compared to the objectives of the power reforms. A similar trend in increase appeared in technical efficiency change, TEFFC with minimum of 0.09949 in 1970 and maximum of 1.8724 in 2010. TEFFC increased from 0.09949 in 1970 to 1.0096 in 1996 and nosedives to 0.87603 in 2000. This suggests the necessity of the reform in 2001. TEFFC has been slightly greater than unity in the periods after 2001 as shown in Figure 7. TEFFC is defined as the diffusion of best-practice technology in the management of activity (Ade .I et al., 2011). This is attributed to investment planning, technical experience and management and organization in power stations.

The result in table 2 shows that there have been slight improvements in appropriate investment planning, technically skilled staff and management in the sector.

The result shows that the change in TECHC is epileptic. TECHC nosedived from a peak value of 1.4434 in 1970 to 1.000 in 2001 (the benchmark year) and still fell to 0.79009 in 2010 . As a consequence of innovation, technological change occurs, that is adoption of new technologies by best-practice power plant (Ade .I et al., 2011). This also reveals the effect of routine maintenance on the plants. After the reform in 2001, TECHC is less than one for all the years which indicates technological regress (TECHC $<1$ ) while the year 2007 experienced technological improvement (TECHC > 1). The reform has practically not impacted very positively on TECHC of the sector. Figure 8 shows the plot of TECHC.

Table 2: Results for Annual Productivity Index

\begin{tabular}{|l|l|l|l|}
\hline YEAR & TEFFC & TECHC & MALM \\
\hline 1970 & 0.08458 & 1.5807 & 0.13370 \\
\hline 1973 & 0.13876 & 1.1158 & 0.15483 \\
\hline 1976 & 0.22007 & 0.93838 & 0.20651 \\
\hline 1980 & 0.37195 & 1.2459 & 0.46343 \\
\hline 1983 & 0.45469 & 1.1177 & 0.50822 \\
\hline 1986 & 0.56187 & 1.2053 & 0.67722 \\
\hline 1990 & 0.70653 & 1.0856 & 0.76703 \\
\hline 1993 & 0.77163 & 0.98053 & 0.75661 \\
\hline 1996 & 0.88439 & 0.87836 & 0.77682 \\
\hline 1999 & 0.85285 & 1.0933 & 0.93241 \\
\hline 2000 & 0.79390 & 1.1732 & 0.93138 \\
\hline 2001 & 1.0000 & 1.0000 & 1.0000 \\
\hline 2003 & 1.2503 & 0.83173 & 1.0399 \\
\hline 2004 & 1.3705 & 0.75941 & 1.0408 \\
\hline
\end{tabular}




\begin{tabular}{|l|l|l|l|}
\hline 2005 & 1.3387 & 0.81777 & 1.0948 \\
\hline 2006 & 1.2635 & 0.90661 & 1.1455 \\
\hline 2007 & 1.1822 & 1.0770 & 1.2733 \\
\hline 2010 & 1.8418 & 0.76002 & 1.3998 \\
\hline
\end{tabular}

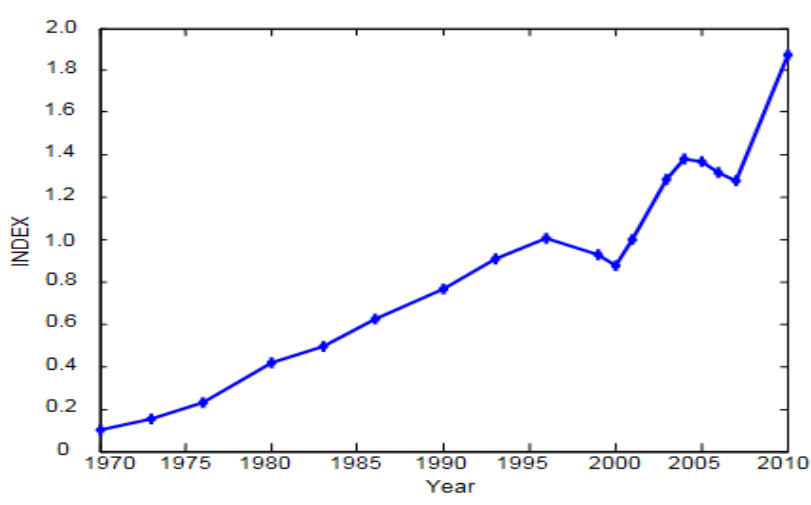

Figure 7: Technical Efficiency (TEFFC)
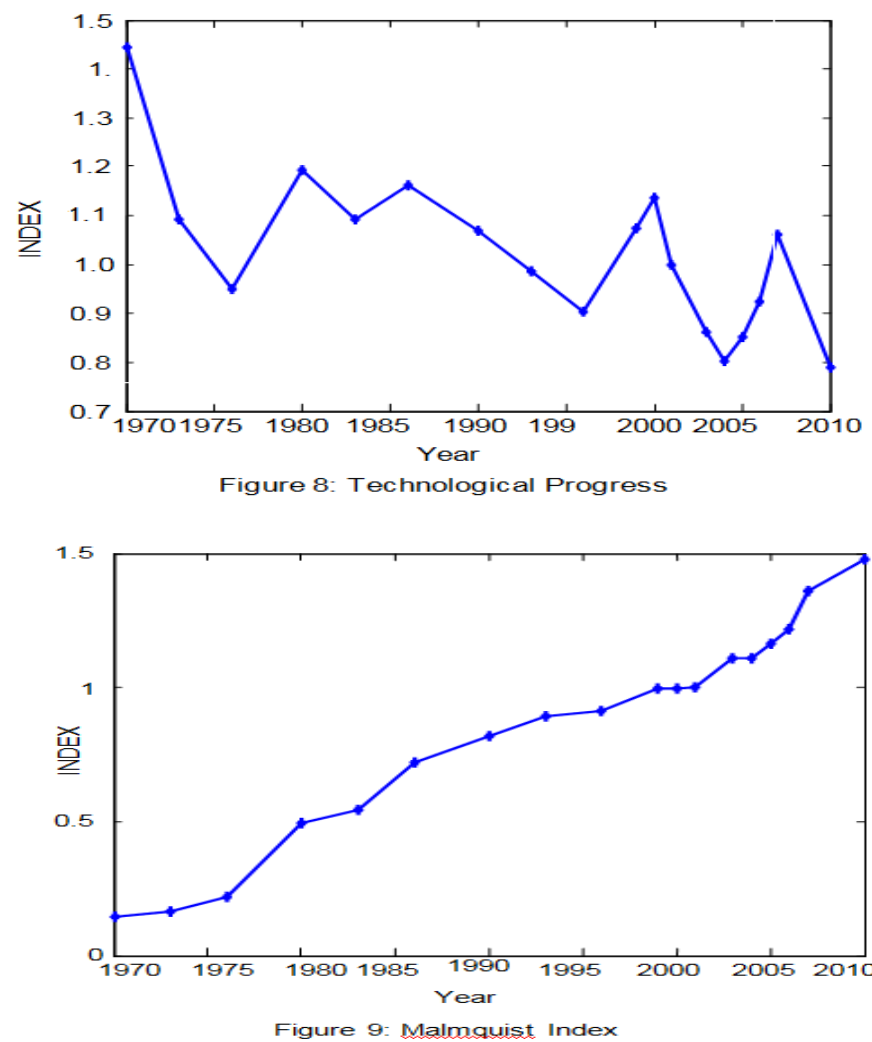

\section{Conclusion}

The research reveals that less than $46 \%$ of the power sector's plant installed capacity was available for the period under review. Constant vandalism and attack on gas pipeline, PHCN's indebtedness to Nigerian Gas Company and age of the plants have been adduced for the above scenario. The load factor rose from $58.38 \%$ in 1970 to $68.65 \%$ in 2001 during pre- reform era and later to $91.42 \%$ in 2010 during post-reform era, as against international best-practice of $80 \%$. Average availability of plants was less than $46 \%$ as against industry bestpractice of over $95 \%$. The capacity factor was of similar range of less than $45 \%$. Low capacity factor signifies that the average energy generation is low. This implied that the plants downtime is high during the periods under survey. There is a significant reform impact on plants' load factor with little or no impact on utilization and capacity factors. This arose from the fact that the installed capacity has been on steady increase with little or no improvement on maintenance culture, technical awareness and rapid fault response. 
The maximum loss power at each downtime had been on the increase with increase in installed capacity as a result of PHCN's inability to do adequate routine maintenance on the plants and fault development. Plants can be idle due to network failure or lack of gas supply.

The research shows the reflection of the gross technical inefficiency and technological setback in the power system. A number of reasons could be adduced to be responsible for this shortfall in performance. These include: low plant availability due to breakdowns/failures, overdue overhaul of units, obsolete technology relative to advancement in the field, instability of the national grid system, ageing of plant components, disruption in gas supply, among others. Measures to improve the performance indices of the plant includes: training of Operational and Maintenance (O\&M) personnel regularly, improvement in O\&M practices, proper Performance Evaluation of all Power Station, organizing regular management meetings and improve general housekeeping of the plant. Other measure is elimination or minimization of concerns about security of supply of gas associated with resource control agitation in Niger-Delta region. Credible and decisive effort to eliminate tension is more urgent than ever before.

The role of insufficient operational capacity due to ageing facilities that are poorly maintained on poor service provision is indisputable. The conceptual objective of the power reforms to remedy inadequate power generation capacity, inefficient usage of capacity, ineffective regulation and high technical losses has been minimally achieved.

The study recommends that a routine investigation and evaluation of policies and strategies be put in place to periodically ascertain its effectiveness and efficiency. There should be immense drive to harness other sources of electric not just limiting to and expanding on same energy source. The country is blessed with large amount of renewable energy resources like hydropower, solar, wind and biomass which will not only boost quantity and quality of electricity but also its reliability. There should be professional training for power sector staff and management to guarantee technical efficiency of personnel. This will ensure skilled and routine maintenance of the plants.

\section{References}

[1] Ade .I, Carlos .P.B and Shunsuke .M (2011) "Nigeria's Power Sector: Analysis of Productivity". Working Paper. Department of Economics, School of Economics and Management, Technical University of Lisbon.

[2] Adenikinju, Adeola F., 1998. "Productivity Growth and energy Consumption in the Nigerian Manufacturing Sector: A panel data analysis." Energy Policy, 26, 3, 199-205

[3] Adeola .A (2005). "Analysis of the Cost of Infrastructure Failures in a Developing Economy: The Case of the Electricity Sector in Nigeria". African Economic Research Consortium, Nairobi Feb 2005.

[4] Adeola .A (2008). "Electricity: Crisis Without End". Guardian Editorial, May 12, 2008.

[5] Adoghe, A. U., 2008. "Power Sector Reforms in Nigeria - Likely Effects on Power Reliability and Stability in Nigeria",http://www.weathat.com/power-sector-reforms-in-a2219.html accessed on 20/08/11

[6] Akunbulire, T. O.; Awosope, C. O. A. and Oluseyi, P. O. (2007). "Solving the Technical Problems Facing Electrical Energy Development in Nigeria", 3rd Annual Conference Research and Fair of the University of Lagos, Nigeria, December 3, Pp. 175-181.

[7] Agbo A (2007). "Ending the Power Nightmare." TELL Magazine, May, 2007. pp.28-31 Bao Hong, Tan. (2008) "Cobb-Douglas Production Function" Barros C. P. (2008). "Efficiency analysis of hydroelectric generating plants: A case study for Portugal". Energy Economics, Vol 30, 59-75.

[8] Club De Maris, (2000). "Energy and Democratic Leadership: Promoting Access to Energy For Poverty Reduction". www.clubmadrid.org/cmadrid/index

[9] Ekeh, J. C. (2008). "Positioning the Power Sector for Electricity Sufficiency in Nigeria to Meet Up with Vision 2020", 20th Covenant University Public Lecture Series, March 27, 2008, Ota, Nigeria.

[10] Ekeh, J. C. (2001). "Evaluation of the Technico-Economical Indices of Major Power Stations Operation in Nigeria", Journal of Engineering Science and Applications. 3(1): 1-21.

[11] ESMAP (1993). "Nigeria: Issues and Options in the Energy Sector". July 1993.A Joint Report with the World Bank Western African Development Industry and Energy Division.

[12] Estache .A et al (2008). "How Efficient are African Electricty Companies?" Evidence from the Southern African countries. Energy Policy, 36 (6): 1969-1979.

[13] Garba .B and Sambo A.S et al (2009).

[14] "Electricity Generation and the Present Challenges in the Power Sector".

[15] Hoyt .N and Kennedy-Darling .J et al (2008), "The Energy Crisis of Nigeria: AnOverview and Implication for the Future". University of Chicago.

[16] IEA (2002). "Energy and Poverty". IAEA Bulletin, Paris: International Energy And Democratic Agency, pp 24-29.

[17] Ikeme .J and Obas John (2005). "Nigeria's Electric Power Sector Reform: What Should Be The Objective?” Energy Policy 33: 1213-1221.

[18] Isaac F.O and Obodeh .O (2011), "Performance Analysis for Sapele Power Station; Case Study for Nigeria”. Journal of Engineering Trends in Engineering and Applied Science (JETEAS)2(1):166-177.

[19] Iwayemi .A. (2008[a]). "Investment in Electricity Generation and Transmission in Nigeria: Issues and Options". International Association for Energy Economics. First Quarter 2008.

[20] Iwayemi A. (2008[b]) "Nigeria Dual Energy Problems: Policy Issues and Challenges". Internatinal Association of Energy Economics, Fourth Quarter, pp 17-21.

[21] Isola, W.A., (2011). "Market Structure in the Restructuring of the Nigerian Electricity Industry". The Journal of Energy and Development. Volume 34, Number 2.

[22] Jamasb .T and Pollitt .M (2001). "Benchmarking and regulation: International Electric experience”. Utilities Policy, 9, pp. 107-130.

[23] Kleit .A.N and Terrell .D, (2001), "Measuring potential efficiency gains from deregulation of electricity generation: a Bayesian approach". Review Of Economics and Statistics. pp. 523-530. 
[24] Kofoworola, O. F. (2003). "TowardsImproving Electricity Generation in Nigeria: A Conceptual Approach, Proceedings of the International Conference on Mechanical Engineering 2003 (ICME2003) December 26-28, 2003.

[25] Labo, H.S (2010), "Current Status and Future Outlook of the Transmission Network". Investors Forum for Privatization of PHCN Successor Companies.

[26] Lukman .R (2003). Energy Commission of Nigeria "National Energy Policy". Federal Republic of Nigeria.

[27] Makoju J (2002). "The 2002 Project Plan: Why we are bent on Network Expansion." NEPA Review, Oct-Dec, 2002. pp. 12-14.

[28] Makoju J.O (2007) "A Presentation to the Presidency on Power Sector Status, Issues

[29] Malmquist .S (1953). "Index Numbers and Indifference Curves". Trabajos de Estatistica (4)

[30] Manafa.N (1995). "Electricity Development in Nigeria". Rasheen Publishers,Lagos. Pp 37-51.

[31] NERC. "Distribution Code for the Nigeria Electricity Distribution System". Version 1 Obadote .D.J (2009). "Energy Crisis in Nigeria: Technical Issues and Solutions". Power Sector Prayer Conference June 2009.

[32] Okafor.E.E (2008). "Development Crisis of Power Supply and Implications for Industrial Sector in Nigeria". Stud. Tribes Tribals, 6(2): 83-92.

[33] Okoro .I.O and Chikuni, (2007). "Power Sector Reforms in Nigeria: Opportunities and Challenges". Journal of Energy in Southern Africa, Vol.18, No. 3.

[34] Okoye .J.K (2007). "Background Study on Water and Energy Issues in Nigeria". The National Consultative Conference on Dams and Development, 2007.

[35] Omachonu, J. and A. Chiejine,(2009). "Hope of Stable Power Dims as Afam Loses 450 Mega Watts". BusinessDay, 31 July 2009.

[36] Pollitt M.G, (1996). “Ownership and Efficiency in Nuclear Power Production”. Oxford Economic Papers, 48, pp. 342-360.

[37] Sambo A.S (2008). "Matching Electricity Supply With Demand In Nigeria" International Association of Energy Economics. Fourth Quarter 2008. Tallapragada, Prasad V. S. N., (2009).

[38] "Nigeria's Electricity Sector - Electricity And Gas Pricing Barriers", International Association for Energy Economics, First Quarter 2009.

[39] World Bank (1993), "Nigeria: Issues and Options in the Energy Sector”. UNIDO/World Bank Energy Assessment of Nigeria.World Bank (2005). "African Development Indicators". Washington DC 